\title{
A Organização das Nações Unidas e o uso das línguas
}

\author{
Laura Janaina Dias Amato (UNILA)* \\ https://orcid.org/0000-0003-0339-1185
}

Pablo Ávila Militão (UNILA)**

https://orcid.org/0000-0002-3430-7196

\section{Resumo:}

O presente artigo tem como objetivo apresentar o uso das línguas na Organização das Nações Unidas (ONU). Para tal discussão trouxemos um breve histórico sobre a criação da ONU, para compreendermos as relações das línguas mantidas no e através do discurso fundacional. A partir disso exporemos como foi determinado o estabelecimento dos idiomas de trabalho e oficial da ONU, a partir de sua criação histórica, de base europeia e estadunidense. Com isso, buscamos mostrar que os discursos presentes em alguns documentos da organização não abordam explicitamente o uso institucional das línguas, mantendo assim as relações já pré-estabelecidas.

Palavras-chave: Políticas de linguísticas; ONU; relações de poder; discurso.

\section{Abstract:}

\section{The United Nations and the language use}

This article aims to present the functioning of languages in the United Nations (UN). For this, a brief history of the creation of the UN was necessary to understand the language relations maintained in and through the foundational discourse. From this we will try to show how the establishment of working and official languages of the United Nations was determined, from its historical creation, with a European and American base. Thus, we seek to show that the discourses present in some of the organization's documents do not explicitly address the institutional use of languages, thus maintaining pre-established power relations.

Keywords: Language policies; UN; power relations; Discourse.

* Docente da área de Letras e Linguística, no Instituto Latino-Americano de Arte, Cultura e História, da Universidade Federal da Integração Latino-Americana (UNILA), Foz do Iguaçu-PR-Brasil.

E-mail: laura.amato@unila.edu.br

** Mestrando no Programa de Pós-graduação em Relações Internacionais, Instituto de Economia e Relações Internacionais, Universidade Federal de Uberlândia (UFU), Uberlândia - MG - Brasil.

E-mail: militaopablo@gmail.com 


\section{Introdução}

Espaços de encontros internacionais consistem em importantes ambientes que auxiliam na compreensão sobre trocas linguísticas entre grupos de falantes de línguas diferentes. Nesse aspecto, a Organização das Nações Unidas, doravante ONU, se apresenta como um relevante ambiente de reunião internacional, possuindo o maior número de grupos linguísticos distintos reunidos em um único espaço de diálogo, uma vez que tal fórum é composto por 193 Estados-membros. Em locais de encontro multilíngues é possível observar como ocorrem as relações de fala e quais os idiomas mais utilizados entre os sujeitos. No entanto, essa relação é modificada nas organizações internacionais, pois são espaços institucionalizados através de uma burocracia e um sistema de coordenação que organiza tais reuniões, estabelecendo quais são as regras de comunicação entre os sujeitos.

Dessa forma, este artigo tem como objeto de estudo central o sistema linguístico da ONU e a relação entre os grupos linguísticos que exercem maior domínio sobre o uso da palavra nesse ambiente. Por ser uma organização internacional de vasta atuação em inúmeros assuntos no âmbito global é constituída por órgãos principais e subsidiários, comissões técnicas e regionais, departamentos e escritórios, programas, fundos e agências especializadas. É preciso delimitar, portanto, os espaços de encontro que serão analisados por este trabalho, sendo escolhidos os cincos principais órgãos da instituição (Assembleia Geral, Conselho de Segurança, Conselho Econômico e Social, Secretariado, Corte Internacional de Justiça, Conselho de Tutela) e a agência especializada da ONU para a educação, a ciência e a cultura (UNESCO).
A partir disso, este trabalho procura responder a seguinte pergunta: como são as relações de poder que rodeiam as práticas linguísticas da Organização das Nações Unidas. Para isso, inicia-se na primeira seção a apresentação dos principais conceitos, perspectivas e debates sobre o estabelecimento desse fórum internacional, apontando para os principais atores internacionais que estabeleceram seu funcionamento. Em seguida, analisamos alguns documentos dessa organização internacional, buscando compreender a construção de seu ordenamento linguístico e a disposição desses nos diferentes organismos institucionais criados.

Por fim, testa-se a hipótese que a prática linguística consiste em uma das diferentes técnicas existentes dentro da ONU que mantem relações de posição de poder e de controle entre grupos de falantes diferentes. Quanto à metodologia do artigo, opta-se por uma análise de conteúdo de documentos de fontes primárias da ONU, sendo esses a Carta das Nações Unidas, estatutos internos dos principais órgãos, resoluções da Assembleia Geral e conteúdos disponibilizados no endereço eletrônico oficial daquele organismo. A análise de conteúdo consiste em uma metodologia essencial para este trabalho, visto que se propõe a analisar as significações do texto, a forma e a distribuição de seu conteúdo, procurando observar as informações também do contexto em que os documentos foram escritos (BARDIN, 2011).

\section{Genealogia da Organização das Nações Unidas}

A criação da Organização das Nações Unidas, doravante ONU, se desenvolve em torno de diferentes variáveis, e consequentemente, apresentar somente um fator histórico que 
a compôs ou como um "acidente" histórico que permitiu sua formação seria uma maneira didática na qual se esconderiam distintos processos, como as relações de dominação entre diferentes grupos participantes desde o momento da criação da ONU. Desse modo, para uma compreensão mais profunda dos fatores que a compuseram, não é necessário buscar na história a origem do objeto de estudo, a essência de algo naquilo que esse possui de mais verdadeiro, aquilo que Michel Foucault (1979, p. 19), retomando de Nietzsche, apresentou como Ursprung (origem). É preciso recorrer à genealogia, observar os discursos que a formaram e auxiliaram na criação de uma instituição carregada de legitimidade e autoridade.

Entretanto, estabelecer uma visão entre o contexto histórico e os discursos envolvidos não se apresenta como uma tarefa de fácil execução, ainda mais quando se observa o imenso período histórico de tradição das formações de diversas outras organizações internacionais. De acordo com Herz, Hoffman e Tabak (2004, p. 23), as bases para tais instituições são resultados de práticas entre os países europeus ocorridas desde o século XIX, quando essas passaram a ter mais relevância no sistema internacional. Diante dessa realidade, uma Organização Internacional é formada para responder diferentes questões e interesses de grupos diversos, para realizar, de maneira mais institucionalizada, a cooperação internacional (HERZ; HOFFMAN; TABAK, 2004, p. 9). Ela possui, também, um alto aparelho burocrático, com orçamento definido e com servidores internacionais para produzir certa medida de governança global ${ }^{1}$. Tal organis-

10 termo governança global é utilizado para situações em que as normas e regras não são seguidas por uma autoridade formal, logo, por um governo de algum Estado. A governança global é utilizada para definir ambientes em que a coope- mo é resultado de relações multilaterais, “(...) a coordenação de relações entre três e mais Estados de acordo com um conjunto de princípios" (HERZ; HOFFMAN; TABAK, 2004, p. 11), e com uma participação voluntária de seus atores, embora é sabido, em muitas ocasiões, que há uma grande pressão para a adesão na Organização (HERZ; HOFFMAN; TABAK, 2004, p. 16).

A tradição europeia aqui faz referência ao sistema moderno de Estados instituído no continente desde o século XVII, com o marco da Paz de Vestfália. Tal evento corrobora com a construção de uma ordem internacional, visto que, "a Paz de Vestfália é qualificada na Carta Constitucional Europeia, uma vez que encerra um conjunto de normas, estabelecidas mutuamente de modo a definir os detentores da autoridade no cenário internacional europeu, suas prerrogativas e deveres" (ARAÚJO, 2008, p. 72). Dessa forma, uma ordem internacional europeia surge enxergando somente uma entidade como autor legítimo desse espaço: o Estado. A Paz de Vestfália não é somente um marco internacional que introduziu o conceito de soberania, é a concepção de uma nova ordem internacional, em que os atores que a conformaram, respaldados por regras de convivência estabelecidos, puderam introduzir um novo modo de governar em um cenário internacional (KISSINGER, 2014, p. 29).

O Congresso de Viena, ocorrido em 1815, consiste em outro evento que compôs tal tradição anteriormente citada. De acordo com Henry Kissinger (2014, p. 50) entendese que "os Estados conservadores procuravam erguer defesas contra uma nova onda revolucionária; buscavam incluir mecanis-

ração resolve diferentes impasses e gera regras de conduta entre os atores envolvidos. Para mais sobre o termo, lê-se em (ROSENAU; CZEMPIEL, 1992, p. 4). 
mos para a preservação da ordem legítima - que entendiam ser o governo monárquico". A partir disso então, e com o intuito de assegurar um novo ordenamento ao continente europeu, cujo objetivo era redesenhar as fronteiras após a derrota napoleônica, é elaborada a constituição de três conjuntos de instituições através do Congresso de Viena: a Quádrupla Aliança; a Santa Aliança; e, por fim, a concretização de um sistema de conferências diplomáticas periódicas (KISSINGER, 2014, p. 50).

Logo, embora existam outros processos históricos ${ }^{2}$, essas duas experiências genuinamente europeias (a Paz de Vestfália e o Congresso de Viena) compõem um sistema de relações de dominação de um grupo de países a outros países com diferentes níveis de força. Tais relações auxiliaram na construção de um sistema de regras que uns puderam se apoderar melhor e de forma magistral. Para avançar sobre a análise acerca das relações entre os grupos dominantes no sistema internacional que formalizaram a ONU, é preciso ir para as Conferências de Teerã, Moscou, Yalta e Potsdam.

Tais Conferências foram responsáveis pela tentativa em reorganizar o contexto mundial pós Segunda Guerra. Os maiores poderes de decisão estavam, todavia, entre os EUA e a URSS, pois a Grã-Bretanha já havia perdido boa parte de sua influência mundial e nunca voltaria a ser o que fora antes de 1918 (HOBSBAWM, 1995, p. 38). Assim, tais reuniões significaram para o mundo o

2 A exposição de diferentes momentos históricos que relatam o vínculo entre as relações de dominação de um grupo a outro e a criação de Organizações Internacionais ou Tratados Internacionais para exercer um sistema de regras que poucos se apoderam resulta em um extenso trabalho de investigação. Por conseguinte, não será evidenciado outros processos históricos que influenciaram nas práticas desses Organismos Internacionais. ponto alto de uma colaboração entre os EUA e a URSS (VIZENTINI, 1997, p. 8). A sociedade internacional viria a ser organizada e construída, então, de acordo com uma concepção europeia de Estado-nação, independentemente se esse sistema organizacional incluía, de maneira humanitária, satisfatória e representativa, todos os demais territórios mundiais. Em ciência dessa construção de uma ordem de acordo com a tradição europeia, juntamente com os interesses dos países reunidos, ocorreu, durante o período de conferências, o planejamento da criação de uma Organização Internacional que assegurasse o controle da ordem mundial e as vontades de tais aliados. A Organização Internacional é nomeada posteriormente por Organização das Nações Unidas, e assiste seu nascimento, durante o mesmo ano, em 26 de Junho de 1945, a partir da Conferência de São Francisco, ocorrida nos EUA.

Desde o primeiro marco histórico apresentado - a Paz de Vestfália - até as últimas conferências citadas, o que se estabeleceu como resultados foram diferentes exercícios de poder de um grupo sobre o outro. 0 exercício de alguns decidirem o destino dos adversários e derrotados. Os indivíduos que pronunciaram tal narrativa não são neutros, pois esses estão obrigatoriamente de um lado da batalha, encontra-se que "(...) aquele que fala, aquele que diz a verdade, aquele que narra a história, aquele que recobra a memória e conjura os esquecimentos, pois bem, este está forçosamente de um lado ou do outro" (FOUCAULT, 2010, p. 47). Em suma, o discurso exposto terá sempre uma perspectiva, um ponto de vista próprio - é um discurso que se desenvolve dentro de uma dimensão histórica (idem, ibidem) - e, por consequência, faz estabelecer uma verdade que é assegurada por uma posição de combate (FOUCAULT, 2010, p. 45). 
Têm-se, pois, dentro desse percurso, a construção de uma racionalidade e de procedimentos técnicos para manter a vitória do grupo estabelecido no poder, “(...) para fazer calar, aparentemente, a guerra, para conservar ou inverter as relações de força” (FOUCAULT, 2010, p. 46). É uma racionalidade vinculada a uma estratégia para manter as relações de dominação daquele que exerce um poder (FOUCAULT, 2010, p. 47). Em suma, pode-se concluir que, devido à concepção do discurso de uma guerra perpétua, é criado um imaginário de que a justiça; a fórmula da lei e a estabilidade da ordem são elementos necessários para se evitar outra batalha.

\section{Idiomas na ONU}

A ONU estabelece, atualmente, seis idiomas oficiais e de trabalho para o funcionamento de suas atividades, que são: árabe, chinês, espanhol, francês, inglês, russo. A organização é composta pelos seguintes órgãos: Assembleia Geral, Conselho de Segurança, Conselho Econômico e Social, Secretariado, Corte Internacional de Justiça, Conselho de Tutela; e em nenhum momento conseguimos identificar quando houve e qual órgão decidiu a adoção destas línguas. Sabe-se que há uma diferenciação entre língua oficial e língua de trabalho, mas como não houve nenhuma regularização sobre como o sistema ONU estabeleceu suas atividades em seu documento fundacional, cada órgão determina, então, como é estabelecido suas línguas oficiais e de trabalho.

Devido à ausência de regularizações dos idiomas oficiais da ONU, a Assembleia Geral se encarregou de nomear recomendações de quais seriam as possíveis línguas oficias e de trabalho dos demais órgãos, ademais de estabelecer como funcionaria o sistema de uso das línguas internamente. Dessa forma, a primeira escolha de toda a Organização é encontrada na Resolução 2 (I) da Assembleia Geral em 1946, em que se recomenda a seguinte configuração: "los idiomas oficiales en todos los órganos de las Naciones Unidas, aparte del Tribunal de Justicia Internacional, serán chino, francés, inglés, ruso y español; el inglés y el francés serán los idiomas de trabajo." (ONU, 1946). Essa foi a primeira determinação sobre as línguas feita pelo fórum internacional. No entanto, após 78 anos desse marco histórico, é visto que a ONU considera seis línguas oficiais da Organização: o árabe, o chinês, o inglês, o francês, o russo e o espanhol ${ }^{3}$. Por outro lado, tal fonte não apresenta se há idiomas de trabalho ou não no fórum global. Esse dado, retirado do site oficial do organismo, é ambíguo, visto que não se responde o que é ser uma língua oficial deste organismo, nem ao menos responde em quais dos órgãos estabelece essa composição. Como não há um regulamento determinando as relações das línguas nesses espaços, não há como comprovar, e nem ao menos cobrar dos órgãos, tal informação citada pelo endereço eletrônico. Portanto, tal ausência acarreta para cada órgão o estabelecimento de seus idiomas oficiais e de trabalho dentro de cada estatuto interno.

A Assembleia Geral, ainda na Resolução 2 (I), assegura que é de responsabilidade do Secretário Geral a instalação de todo equipamento para a interpretação aos outros idiomas de trabalho da Organização (ONU, 1946). Tal regulamento aprovado pela Assembleia Geral estabelece que o idioma pronunciado em uma das línguas de trabalho, será traduzido a outra língua de trabalho por responsabilidade desse fórum (ONU, 1946). No entanto, os discursos pronunciados em

3 Disponível em: http://www.un.org/es/sections/about-un/official-languages/. Acessado em: 22/02/2018. 
um dos outros três idiomas oficiais será somente traduzido para as duas línguas de trabalho (ONU, 1946). Nota-se, então, uma distinção oculta entre as duas categorias de idiomas: os idiomas oficiais e os idiomas de trabalho.

Por outro lado, é assegurado o direito de qualquer membro se pronunciar em qualquer um dos idiomas que não sejam os oficiais, contudo, é papel da própria delegação a responsabilidade em traduzir qualquer discurso ou ato escrito para um dos idiomas de trabalho (ONU, 1946). As resoluções desse organismo serão publicadas em todos os idiomas oficiais, porém os diários serão publicados somente nos idiomas de trabalho (ONU, 1946). Destarte, é apresentada a primeira referência ao tratamento de idiomas de toda a Organização Internacional, e desde essa Resolução, houve um grande caminho até a composição das línguas atualmente encontrada no Estatuto da Assembleia Geral.

Entre 1948 até 1973, houve adesões aos idiomas de trabalho da Organização, a primeira, em 1948, durante a Resolução 262 (III), em que se incorpora o espanhol ${ }^{4}$; a segunda, em 1968, durante a Resolução 2479 (XXIII), incorporando o russo; e a última, em 1973, durante a Resolução 3189 (XXVIII), incorporando o chinês; e a Resolução 3190 (XXVIII), incorporando o árabe. Ainda

4 Observa-se que os seguintes países se posicionaram contra a essa primeira adesão: Austrália, Bélgica, Bielorrússia, Canadá, China, Checoslováquia, Dinamarca, França, Islândia, Luxemburgo, Holanda, Nova Zelândia, Noruega, Polônia, Suécia, URSS, Reino Unido, EUA e ex-República Iugoslava da Macedônia. Os países que se posicionaram a favor consistem em: Argentina, Bolívia, Brasil, Chile, Colômbia, Costa Rica, Cuba, República Dominicana, Equador, Egito, El Salvador, Etiópia, Grécia, Guatemala, Haiti, Honduras, Irã, Líbano, Libéria, México, Nicarágua, Panamá, Paraguai, Peru, Filipinas, Arábia Saudita, Síria, Turquia, Uruguai, Venezuela e Iêmen. nesta última Resolução de 1973 é aderido também o árabe como um idioma oficial da Assembleia Geral, tomando nota que os Estados membros árabes custearam por três anos a consequência da mudança do estatuto interno do órgão.

O próximo passo histórico a compor o cenário linguístico da Assembleia Geral está definido pela Resolução 3355 (XXIX), de 1974, em que a língua alemã também passa a ser usada para a tradução dos documentos oficiais, resoluções e decisões do Conselho de Segurança, do Conselho Econômico e Social e da Assembleia Geral (ONU, 1974). Não obstante, tal idioma não chega a receber o status de língua de trabalho ou oficial. A razão desse fato incide em quais sujeitos executarão tal política, os países de língua alemã, Áustria, República Democrática Alemã e República Federal da Alemanha ${ }^{5}$, serão, de forma conjunta, os contribuintes sobre todos os gastos que tal ação demandar (ONU, 1974). Dessa forma, a língua alemã não receberá os privilégios de uma língua oficial ou de trabalho da Organização, uma vez que a ONU não se responsabilizará sobre tais gastos. A Resolução supracitada somente enuncia a preocupação de certos países de língua alemã pela tradução de documentos relevantes no cenário internacional; o reconhecimento da importância desses documentos para sua população; e falta de interesse da Organização em adequar mais uma língua em seu corpo linguístico oficial ou de trabalho (ONU, 1974).

As entidades responsáveis pela execução do funcionamento paritário dessas seis línguas - com exclusão do alemão - dentro da Assembleia Geral são de responsabilidade da Secretaria. Durante o capítulo VII, do es-

5 Observa-se que a República Democrática Alemã e a República Federal da Alemanha constituem, atualmente, um mesmo país: a República Federal da Alemanha. 
tatuto da Assembleia Geral ${ }^{6}$, é estabelecido pelo Artigo 47 que: "La Secretaría recibirá, traducirá, imprimirá y distribuirá los documentos, informes y resoluciones de la Asamblea General, sus comisiones y sus órganos; interpretará a otros idiomas los discursos pronunciados en las sesiones." Assim, é finalizado a composição das línguas do principal órgão das Nações Unidas: a Assembleia Geral, um espaço que se diz universal e de encontro de diferentes culturas com uma estrutura cristalizada por processos históricos em seis pré-determinados idiomas oficiais e de trabalho. É através do Departamento para a Assembleia Geral e Gestão de Conferências (DGACM), um dos departamentos da Secretaria, que o órgão atua sobre as obrigações perante o funcionamento pleno das seis línguas em todas as reuniões das Nações Unidas, incluindo suas sedes fora do continente americano, responsável também pelo funcionamento das reuniões e das documentações oficiais daquele órgão.

Em continuidade a isso, o Conselho de Segurança é outro órgão que, atualmente, possui a mesma estrutura que a Assembleia Geral, definida pelo Artigo 41 de seu estatuto interno. Da mesma forma, os discursos pronunciados em um desses seis idiomas, serão interpretados aos outros cinco idiomas. Ainda assim, cada Estado membro obtém o direito de se pronunciar na língua que for de seu interesse, sendo que os custos de todo o trabalho de tradução e impressão dos documentos deverá ser de responsabilidade de tal membro. As Resoluções e demais documentos também serão publicadas somente nos seis idiomas oficiais e de trabalho do Conselho de Segurança. Tal composição não se originou dessa forma, em junho de 1946,

6 Disponível em: http://www.un.org/es/comun/ docs/?symbol=A/520/rev.18. Acessado em: 23/02/2018. inicialmente, foram adotados somente cinco idiomas oficiais - russo, chinês, espanhol, francês e inglês - e dois desses como idiomas de trabalho - inglês e francês. Em seguida, foi a vez dos idiomas espanhol e russo receberem o status de idiomas de trabalho, presente na Resolução de 263 de 1969. Tal modificação foi uma consequência de uma recomendação anterior vinda da Assembleia Geral. 0 mesmo processo ocorreu também com a adesão do chinês como língua de trabalho, em janeiro de 1974, e, por último, com o árabe em 1982, esse recebendo a categoria de idioma oficial e de trabalho ao mesmo tempo.

Esses são os únicos órgãos principais que estabelecem uma similaridade sobre o cenário linguístico de seu regimento interno. O Conselho Econômico e Social, por sua vez, estabelecem como língua oficial o árabe, o chinês, o russo, o inglês, o francês e o espanhol, e como língua de trabalho somente o espanhol, o francês e o inglês (ONU, 1992). Sua única modificação ao documento atual se deu em abril de 1982, aderindo o árabe como um idioma oficial (ONU, 1992). Assim, as diferenças entre uma categoria e outra se encontram na produção de documentos, dado que embora as resoluções e outras decisões oficiais do órgão sejam interpretadas em todas as seis línguas, as atas somente serão publicadas nos três idiomas de trabalho. Como já informado, a secretaria também é responsável pela tradução e distribuição de todos documentos oficiai.

Em contrapartida, uma agência subsidiada ao Conselho Econômico e Social, a UNES$\mathrm{CO}^{7}$, estabelece como línguas oficiais os se-

7 De acordo com a própria agência, a UNESCO, fundada em 16 de novembro de 1945, tem como objetivo procurar o diálogo entre as civilizações para a construção da paz através da cultura, ciência e educação.Ver mais site oficial da UNESCO: http://unesdoc.unesco.org/ima- 
guintes idiomas: árabe, chinês, espanhol, francês, hindi, inglês, italiano, português e russo. Em seu estatuto consta que qualquer Estado membro poderá solicitar o emprego de seu idioma com o status de língua oficial dentro desse organismo (UNESCO, 2020, p. $46)^{8}$. Porém, as línguas de trabalho são compostas somente por aquelas seis línguas oficiais da ONU (UNESCO, 2020 p. 45), estabelecendo, assim, distinções entre o emprego de cada idioma. É identificado que todos os documentos de trabalho serão interpretados para as seis línguas de trabalho, em contrapartida, o emprego das línguas oficiais é utilizado somente para a tradução da Constituição de tal organismo (UNESCO, 2020, p.46). Ainda assim, é oferecido o direito à qualquer delegação traduzir um documento da UNESCO para o idioma de sua preferência, sendo que deverá proporcionar os recursos necessários à tal ação ${ }^{9}$ (UNESCO, 2020, p. 45-46).

O Secretariado é outro órgão com uma composição de línguas diferente daquela recomendada pela Assembleia Geral. Embora reconheça as seis línguas oficiais da Organização como também sendo seus idiomas oficiais, as línguas de trabalho do Secretariado se limitam somente entre o inglês e o francês. Por conseguinte, o órgão que contém o mais alto cargo de toda a ONU, aquele que é também responsável por outro departamento, o DGACM, encarregado pela interpretação e distribuição dos documentos- isto é, pela manutenção do suposto multilinguismo da Organização - não execu-

ges/0014/001473/147330s.pdf. Acessado em: 10/06/2018.

8 Disponível em: http://portal.unesco.org/es/ev. php-URL_ID=48895\&URL_DO=DO_TOPIC\&URL_ SECTION=201.html. Acessado em: 07/04/2021.

9 A mesma situação de arcar com os custos se repete no emprego de qualquer outra língua, que não for um idioma de trabalho, na pronúncia do discurso de qualquer membro. ta a igualdade e o equilíbrio entre todos os idiomas oficiais descritos pela ONU.

A Corte Internacional de Justiça é a instituição com menos diversidade linguística, tendo essa conservado seu sistema de uso de línguas intacto desde sua criação. De acordo com o capítulo III de seu estatuto, as únicas línguas oficiais serão o francês e o inglês ${ }^{10}$, sendo assim, reserva-se o direito de que o processo jurídico seja proferido em francês ou em inglês, como as partes preferirem (ASSEMBLEIA GERAL DA ONU, 1945, p. 79) ${ }^{11}$. Dessa forma, aqui se encontra outro exemplo da situação das línguas da Organização Internacional, que embora tenha afirmado que seus idiomas oficiais serão as seis línguas listadas, há ainda organismos que não incorporaram tal recomendação. Ou ainda, mesmo que um órgão tenha tais idiomas listados com o status de língua oficial, seus idiomas de trabalho seguem com disparidades.

Ademais, como um último ponto a ser ressaltado, observa-se que além da ausência de uma política pontual sobre uma o uso das línguas na organização, esse fórum internacional também falha em não conceituar o que configura cada status idiomático de seu organograma. 0 que se compreende por idioma oficial e idioma de trabalho é dúbio até mesmo para a própria organização, uma vez que a carência dessa política é demonstrada no Documento da Assembleia Geral $32 / 237^{12}$, produzido com o auxílio da ins-

10 Não há nenhuma referência sobre a existência de línguas de trabalho para este órgão. Nesse aspecto, o estatuto interno da Corte Internacional de Justiça somente reconhece a categoria de idioma oficial para o uso de suas atividades.

11 Disponível em: https://nacoesunidas.org/wpcontent/uploads/2017/11/A-Carta-das-Na\%C3\%A7\%C3\%B5es-Unidas.pdf. Acessada em: 26/02/2018.

12 Disponível em: https://digitallibrary.un.org/record/660422/files/A_32_237-EN.pdf. Acessado em: 03/03/2018. 
peção realizado pela Dependência Comum de Inspeção (DCI $)^{13}$, em que, desde 1977, não conseguiram determinar com clareza a distinção entre as duas categorias linguísticas mencionadas. Desse modo, o simples conceito de "idioma oficial" e de "idioma de trabalho" não é relacionado a nenhum significado de imediato, tais denominações não implicam, portanto, legalmente em nenhuma interpretação.

Com o intuito de sintetizar as informações analisadas por esta seção, apresentamos duas tabelas e um gráfico. A Tabela 1 evidencia as línguas oficiais e de trabalho utilizadas por cada órgão e agência analisa- dos anteriormente. Em seguida, a Tabela 2 expõe, então, a quantidade de vezes somadas que cada idioma foi empregado durante a escolha linguística de tais organismos. Tais dados são aplicados para a conformação do Gráfico 1, que evidencia a porcentagem da soma da representatividade que cada língua possui nesses espaços. No entanto, é importante notar que tais dados revelam apenas a aplicação de cada língua dentro do sistema de regras e normas da ONU, assim, não é possível ler, através do gráfico, a quantidade e a empregabilidade que cada idioma possui durante a rotina desses organismos.

Tabela 1: Sistema Linguístico das Nações Unidas

\begin{tabular}{|l|ll|}
\hline Orgão & Idiomas Oficiais & \multicolumn{1}{l|}{ Idiomas de Trabalho } \\
\hline Assembleia Geral & A, C, E, F, I, R & A, C, E, F, I, R \\
\hline $\begin{array}{l}\text { Conselho de Segurança } \\
\text { Conselho Econômico e } \\
\text { Social }\end{array}$ & A, C, E, F, I, R & A, C, E, F, I, R \\
$\begin{array}{l}\text { Secretariado } \\
\begin{array}{l}\text { Corte Internacional de } \\
\text { Justiça }\end{array}\end{array}$ & A, C, E, F, I, R & E, F, I \\
$\begin{array}{l}\text { Organização das Naçōes } \\
\text { Unidas para a Ciência, } \\
\text { Educação e Cultura }\end{array}$ & A, C, E, F, H, I, IT, P, R, & A, C, E, F, I, R \\
\hline
\end{tabular}

Legenda: A: Árabe; C: Chinês; E: Espanhol; F: Francês; H: Hindi; I: Inglês; IT: Italiano; P: Português; R: Russo. Fonte: Elaboração própria. Dados extraídos de Estatutos Internos de cada organismo analisado.

13 A Dependência Comum de Inspeção é um organismo criado pela Resolução da Assembleia Geral (A/ RES/31/192), com a finalidade de investigar os assuntos que refletem no funcionamento do trabalho dessa Organização Internacional (A/RES/31/192, 1976, p. 2). Ver mais no seguinte endereço eletrônico: http://www.un.org/es/comun/docs/?symbol=A/RES/31/192. Acessado em: 02/03/2018. 
Tabela SEQ Tabela ${ }^{*}$ ARABIC 2: A Participação de Idiomas no Sistema Linguístico das Nações Unidas

\begin{tabular}{|c|c|}
\hline $\begin{array}{c}\text { Idiomas } \\
\text { Árabe }\end{array}$ & $\begin{array}{c}\text { Quantidade de vezes utilizados } \\
\text { em idiomas oficiais ou de } \\
\text { trabalho }\end{array}$ \\
\hline Chinês & 8 \\
\hline Espanhol & 8 \\
\hline Francês & 9 \\
\hline Hindi & 11 \\
\hline Inglês & 1 \\
\hline Italiano & 11 \\
\hline Português & 1 \\
\hline Russo & 1 \\
\hline
\end{tabular}

Fonte: Elaboração própria. Dados extraídos de Estatutos Internos de cada organismo analisado.

Gráfico 1: A porcentagem da utilização de cada idioma no sistema linguístico dos Estatutos Internos observados.

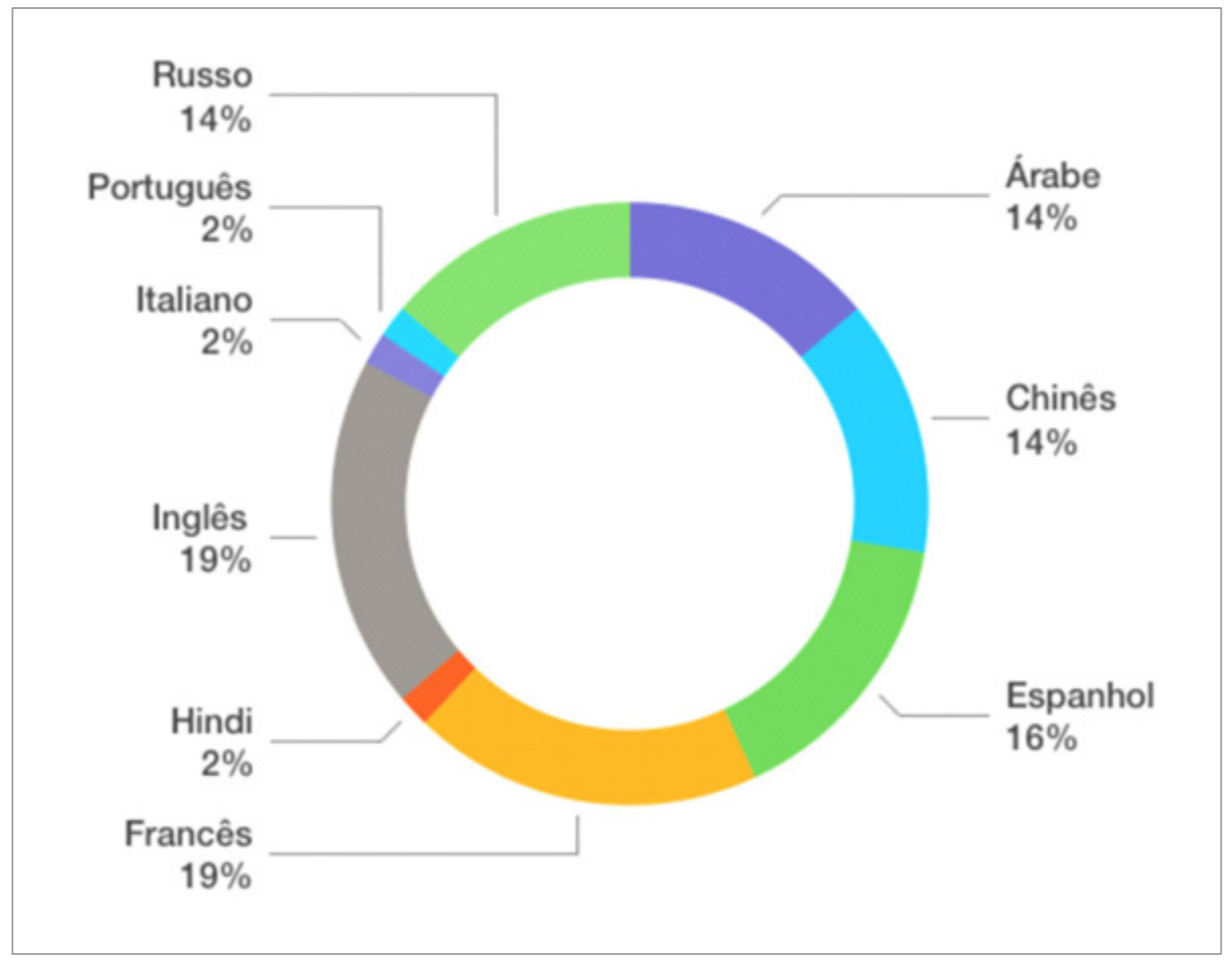

Fonte: Elaboração própria. Dados extraídos de Estatutos Internos de cada organismo analisado. 
Por fim, verifica-se em todos os seis órgãos principais da ONU que os membros possuem o direito de se pronunciarem em um outro idioma diferente daqueles listados como oficiais ou de trabalho por cada órgão. Nesse sentido, o membro, que optar pelo exercício de tal direito, terá como sua obrigação arcar com todas as responsabilidades e custos de interpretação e produção de documentos e discursos. Logo, após o conhecimento de tais informações sobre o sistema de uso das línguas da ONU, observa-se que essa instituição - construída com o objetivo de concretizar um espaço de encontro para membros com o interesse em manter a paz, a segurança internacional e a cooperação entre os Estados (ASSEMBLEIA GERAL DA ONU, 1945, p. 5) - não garante a universalidade e a representatividade linguística para seus membros.

\section{Conclusão:}

Com base no que foi apresentado, destacase que a construção da ONU, enquanto Organização Internacional, pode ser observada a partir de influências de diferentes processos históricos genuinamente europeus e em um último período, estadunidenses. Por conseguinte, entende-se que suas atuações e formas de organizar as relações internacionais refletem a realidade de experiências dessas regiões. Para além dessa análise, e a partir de uma abordagem genealógica de tais eventos, é observada a repercussão de um discurso histórico que irá auxiliar na conformação desse fórum global. A concepção de que existiria uma "guerra perpétua" traz como consequência a necessidade de se criar um sistema de regras e técnicas para obter a conservação de relações de poder entre os grupos. Logo, a lei não consiste em um sinônimo de pacificação ou regulação da ordem, uma vez que dentro dessa ordem ainda continua exercendo uma batalha incessante (FOUCAULT, 2010, p. 43).

Compreende-se que cada Estado-membro concorda em assumir o compromisso de adesão a essa instituição sem a convicção de que terá sua voz garantida de interpretação por esse espaço. Assim, nem todos possuem o mesmo direito de fala. Existem Estados-membros que são favorecidos pela escolha linguística dessa instituição, uma vez que as relações de comunicação são estabelecidas por normas e regras em que alguns falantes são beneficiados por tal política. São disparidades encontradas debaixo dos panos, escondidas entre as categorias de idiomas de trabalho e oficial, que constroem relações de dominação entre grupos linguísticos diferentes. É visto a construção de procedimentos técnicos e racionais para manter as relações de dominação entre os grupos, sendo que uma dessas se comporta dentro da escolha linguística dessa Organização Internacional. Desse modo, o fato de a Organização possuir seis idiomas oficiais não condiz com o uso de fato deles, uma vez que não há a implementação de uma política coesa para toda a instituição internacional e, por conseguinte, não possui uma base jurídica clara.

\section{Referências:}

ARAÚJO, M. P. A.. A Ordem Mundial de Vestfália. In: Alexander Zhebit. (Org.). Ordens e Pacis: abordagem comparativa das relações internacionais. Rio de Janeiro: Mauad X, 2008.

ASSEMBLEIA GERAL DA ONU. Carta das Nações Unidas. São Francisco, 1945.

BARDIN, Laurence. Análise de conteúdo. Ed. Almeida. 2011.

FOUCAULT, Michel. Microfísica do poder. Organização e tradução de Roberto Machado. Rio de Janeiro: Edições Graal, v. 15, 1979.

. Em defesa da sociedade: curso 
no Collège de France (1975-1976) tradução Maria Emantina Galvão. - 2. Ed. - São Paulo: Editora WMF Martins Fontes, 2010.

HERZ, Mônica; HOFFMAN, Andrea; TABAK, Jana. Organizações internacionais: história e práticas. Rio de Janeiro: Elsevier Brasil, 2004.

HOBSBAWM, Eric. A era dos extremos. São Paulo: Companhia das Letras, p. 97-118, 1995.

KISSINGER, H. Ordem Mundial. 1. ed. - Rio de Janeiro: Objetiva, 2014.

ORGANIZAÇÃO DAS NAÇÕES UNIDAS (ONU). Resolução da Assembleia Geral das Nações Unidas 2 (I) de 1 de fevereiro de 1946. Disponível em: http://www.un.org/en/ga/search/ view_doc.asp?symbol=a/res/2(i). Acessado em: 18/06/2018.

\section{Resolução da Assembleia Geral das Na-} ções Unidas 3355 (XXIX) de 18 de dezembro de 1974. Disponível em: http://www.un.org/ es/comun/docs/?symbol=A/RES/3355(XXIX). Acessado em: 23/02/2018.
. Regulamento do Conselho Econômico e Social 5715, Rev. 2. 1992. Disponível em: http://www.un.org/es/comun/docs/?symbol=E/5715/Rev.2. Acessado em: 30/03/2018.

ROSENAU, James N.; CZEMPIEL, Ernst-Otto. Governança sem governo: ordem e transformação na política mundial. Brasília:: Editora UnB, 1992.

UNESCO. Reglamento de la conferencia general. Edição 2020. Disponível em: http://portal. unesco.org/es/ev.php-URL_ID $=48895 \& U R L_{-}$ DO=DO_TOPIC\&URL_SECTION=201.html Acesso em 07 de abril de 2021.

VIZENTINI, Paulo G. Fagundes. O Sistema de Yalta como condicionante da política internacional do Brasil e dos países do Terceiro Mundo. Revista Brasileira de Política Internacional, v. 40, n. 1, p. 5-17, 1997.

Recebido em: 08/03/2021

Aprovado em: 26/05/2021

Esta obra está licenciada com uma Licença Creative Commons Atribuição 4.0 Internacional. 